\title{
Changes in Children's Science-Related Career Aspirations from Age 11 to Age 14
}

\author{
Richard Sheldrake $^{1}$ iD
}

Published online: 27 June 2018

(C) The Author(s) 2018

\begin{abstract}
In order to gain insight into which children aspire towards science-related careers and how these aspirations change over time, 7820 children in England from the nationally representative Millennium Cohort Study were considered. Few children $(8.6 \%$ of the cohort) consistently expressed science-related career aspirations at age 11 and again at age 14; more children (15.7\%) changed from expressing other (non-science) aspirations at age 11 to express science-related aspirations at age 14; other children (12.2\%) changed from expressing science-related aspirations at age 11 to express other aspirations at age 14; and the remaining majority of children $(63.5 \%)$ consistently expressed other career aspirations. Children who consistently expressed science-related aspirations had more advantaged family backgrounds, higher proportions of parents working within sciencerelated fields, higher self-confidence (in science, mathematics, and English), higher school motivation, and higher self-esteem, compared to children who consistently expressed other aspirations. Children who changed towards science-related aspirations were more likely to be boys, children from white backgrounds, and children with higher (at age 14) mathematics self-confidence, science self-confidence, school motivation, and self-esteem. Children who changed aspirations towards science were characterised by increasing science self-confidence, while those who changed aspirations away from science were characterised by decreasing science self-confidence. The findings suggest that further support may be beneficial to help ensure that children's aspirations are not unnecessarily limited by family disadvantage; support after age 11 may also benefit from promoting the feasibility of science careers for all children, regardless of gender and ethnicity.
\end{abstract}

Keywords Aspirations · Longitudinal · Social mobility $\cdot$ STEM

Electronic supplementary material The online version of this article (https://doi.org/10.1007/s11165-0189739-2) contains supplementary material, which is available to authorized users.

Richard Sheldrake

rsheldrake@ioe.ac.uk

1 UCL Institute of Education, University College London, 20 Bedford Way, London WC1H 0AL, UK 


\section{Introduction}

Across many countries, science-related fields increase prosperity through industry and innovation (ACOLA 2014; EngineeringUK 2017; Institute of Physics 2012). Children are often encouraged towards science-related careers, so that this prosperity continues and that these careers become more accessible, regardless of someone's personal background or characteristics, so that the science-related workforce becomes more diverse (ACOLA 2013; EACEA 2011; Royal Society 2014). Ideally, science-related careers would be a potential avenue for anyone to gain social mobility and success (Shaw et al. 2016; Social Mobility Commission 2016), but science is often considered less accessible by and/or for people from particular backgrounds and/or with particular characteristics (Institute of Physics 2013, 2014; WISE 2014).

Specifically, in England, relatively few children aspire towards science-related careers and/ or study non-compulsory science subjects, including especially few girls, few children from disadvantaged families, and few children from some minority ethnic backgrounds (Elias et al. 2006; Homer et al. 2014; Royal Society 2008b). Children's aspirations may be facilitated or constrained by many aspects of life, including the following: their family's level of general "advantage" and/or resources, including family socio-economic status (Ashby and Schoon 2010; Bukodi et al. 2015; Moulton et al. 2018); their family's level of science-related advantage and/or resources, including whether family members work within science-related fields (Archer et al. 2015a; DeWitt et al. 2016; Godec et al. 2017); and by their own attitudes concerning science and their beliefs about themselves, including their self-confidence in "doing well" or "being good" at science (Regan and DeWitt 2015; Tripney et al. 2010; Vidal Rodeiro 2007). These various aspects of life are also interrelated, where children's attitudes towards science, for example, may be fostered or limited by their family's background or resources (Archer et al. 2015b).

In order to gain greater understanding of children's aspirations towards science-related careers, it remains important to consider family backgrounds in general, specific sciencerelated backgrounds, and children's own views (Archer et al. 2015b). Specifically, revealing whether children with particular backgrounds and/or views are more or less likely to express science-related career aspirations, and/or are more or less likely to change their views over time, can increase understanding and suggest where support, encouragement, and/or interventions can be focused.

Accordingly, the research presented here considered the nationally representative and longitudinal cohort of children in England from the Millennium Cohort Study, from age 11 (the start of secondary school) to age 14. Firstly, the research aimed to identify (and quantify the relative proportions of) children with consistent aspirations towards science-related careers, consistent aspirations towards careers in other fields, and children who changed their views towards or away from science-related career aspirations over time. Secondly, the research aimed to consider whether these different children were characterised by having similar or different family backgrounds, personal characteristics, and/or personal views (and to quantify the relative magnitudes of any differences). From a wider perspective, the research was orientated towards helping to contextualise and extend existing cross-sectional research and helping to clarify the extent of any disadvantage and/or inequity linked with aspirations (essentially, helping clarify the extent and nature of the underlying issue, such as differences in family background and/or differences in personal views). Accordingly, the findings can help inform educators and wider stakeholders, including those within England, Australia, and 
countries within Europe, who seek to gain greater understanding of children's progressions towards science-related careers (ACOLA 2013; EACEA 2011; Royal Society 2014).

\section{Background}

\section{Children's Aspirations During Secondary School}

Children's aspirations towards science-related careers, expressed during secondary school, have positively predicted whether they subsequently studied science at university (Morgan et al. 2013; Tai et al. 2006) and whether they subsequently worked within science-related fields (Cannady et al. 2014; Schoon 2001). Concurrently, while many graduates and scientists have believed that they always had an interest in science, almost a third of a sample of scientists from the USA (Maltese and Tai 2010; Maltese et al. 2014) and over half of a sample from across Australia and New Zealand (Venville et al. 2013) have reported that their interest developed during secondary school, which highlights the importance of this time.

In England, secondary school starts at age 11/12 (year 7) and continues to age 15/16 (year 11 ), and studying science is compulsory during this time. Students can then undertake uppersecondary education from ages 16/17 to 17/18 (years 12 and 13), where no subjects are compulsory. However, a career in science often requires someone to have studied science at university, which usually requires someone to have studied science at upper-secondary school (Royal Society 2006, 2008a, b). In these circumstances, aspirations during secondary school may be especially important, as some studying choices may potentially enhance or restrict future career options.

Relatively few children in secondary school in England have aspired to be scientists, although science has often been considered to be interesting, relevant for careers, and important within school and wider life (Bennett and Hogarth 2009; DeWitt et al. 2014; Jenkins and Nelson 2005). Nevertheless, it remains somewhat unclear how children's aspirations and attitudes towards science change during secondary school: some attitudes have appeared to decrease, remain similar, or even increase, although these changes have often been inferred from cross-sectional studies that survey different children of different ages (e.g. Bennett and Hogarth 2009; Potvin and Hasni 2014). Such studies have sometimes given contrasting findings, for example where children's perceived usefulness of science has appeared to be higher (Potvin and Hasni 2014) and to be lower (Bennett and Hogarth 2009) in older children compared to younger children, although the samples and methods have unavoidably varied across different studies.

Some, but relatively few, studies have applied longitudinal approaches that survey the same children at different ages (e.g. DeWitt et al. 2014; Sheldrake et al. 2017). For example, for children in England surveyed at age 10/11 and age 12/13, their aspirations towards science-related careers slightly increased over time, while their attitudes towards science (encompassing their interest in science and science being perceived as useful) remained similar (DeWitt et al. 2014). Specifically considering physics, for children in England surveyed at age 12/13 and age 14/15, their intentions towards studying noncompulsory physics and their interest in physics decreased over time, while their perceived usefulness of physics increased (Sheldrake et al. 2017). Nevertheless, only around a fifth to a quarter of the children exhibited consistently positive intentions towards studying physics, and there were indications that more girls than boys moved away from such intentions over time (Sheldrake et al. 2017). 


\section{Influences on Children's Aspirations}

Children's aspirations and other views may be influenced and/or constrained in ways that may ultimately reduce equitable access to science. For example, compared to girls, boys have expressed higher science self-confidence and interest and have perceived science to be more relevant and/or useful to their careers (Bennett and Hogarth 2009; Jenkins and Nelson 2005), yet boys and girls often have similar science attainment (Department for Education 2011; OECD 2015). Children's interests and their other attitudes and beliefs may be influenced by their families, their education, and also by wider socio-cultural norms or expectations. For example, some children view science subjects, such as physics to be masculine and as inherently requiring cleverness (due to being perceived as being hard subjects), which may entail that science is perceived to be less accessible for girls and for those with less selfconfidence in their abilities (Archer et al. 2015b, 2017). Concurrently, parents from Chinese, Indian, and some other minority ethnic backgrounds have often viewed science favourably and conveyed positive views about science and/or science careers to their children; nevertheless, many of these children have still considered science to be generally associated with being male and being white and hence have still perceived science to be less accessible than other fields (Archer et al. 2015b; Aschbacher et al. 2010; Wong 2015).

In more general terms, someone's family background has often been considered to constrain or facilitate their future success: contemporary societies may be systemically inequitable, so that advantage entails more advantage while disadvantage entails more disadvantage (DiPrete and Eirich 2006; Shaw et al. 2016; Social Mobility Commission 2016). For example, the socio-economic status of parents has been associated with the socio-economic status of their children's aspirations and/or of their children's subsequent occupations (Ashby and Schoon 2010; Bukodi et al. 2015; Moulton et al. 2018). Higher levels of parental education have also been associated with children being more likely to subsequently work within science (Eccles and Wang 2016; Wang et al. 2013). Additionally, having access to family support, encouragement, role models, and other aspects of family circumstances have also been associated with children's science-related aspirations and/or choices (Buschor et al. 2014; Maltese et al. 2014; Sjaastad 2012). As a specific example, for children aged around 14 in England, science aspirations have been positively associated with having a family member working within science, the children believing that their parents had positive attitudes towards science, the children's own attitudes towards science (finding science interesting and useful), and the children's engagement in extra-curricular science activities (DeWitt and Archer 2015). Many other studies have highlighted the importance of children's views as influences on their science-related aspirations, especially their self-confidence in science, their interest in science, and how useful studying or working within science is considered to be (Regan and DeWitt 2015; Tripney et al. 2010; Vidal Rodeiro 2007). Nevertheless, there have been indications that these personal attitudes and beliefs, and children's wider identification with science may also be facilitated or constrained by children's family background or educational context (Archer et al. 2012; DeWitt et al. 2011).

\section{Theoretical Perspectives}

The intersection of children's aspirations, personal views, and their family circumstances has been considered through various perspectives in order to explore and/or potentially explain how children may be facilitated or constrained in their lives. 
Some perspectives have focused on quantification or description. For example, the influence of family backgrounds on children has often been illustrated through the socio-economic status of parents' occupations associating with the subsequent socio-economic status of their children's occupations (e.g. Bukodi et al. 2015; Macmillan et al. 2015). Within such work, the transmission of advantage or disadvantage to children has remained somewhat unclear in terms of how, exactly, it operates or occurs but has often been assumed to be "cumulative" (DiPrete and Eirich 2006); for example, disadvantaged children may be less likely to achieve at school, (therefore) less likely to attend or be able to attend university, and (therefore) less likely to enter occupations that may require high or particular qualifications (Crawford et al. 2016; Macmillan et al. 2015). Nevertheless, many diverse factors may be relevant.

Sociological perspectives, such as those proposed by Pierre Bourdieu (e.g. Bourdieu 1984), suggest that someone's background may influence their preferences, dispositions, and other internalised beliefs that are used to understand the world (someone's habitus), which intersects with formal and informal expectations within fields (such as norms and expectations within education, or within wider domains such as science); someone's actions are then influenced by their habitus and facilitated or constrained by their available capital (their available resources, such as cultural capital, social capital, economic capital, and/or more specific forms of capital), within the context of different fields (Bourdieu 1984). Those who are already advantaged within society are theorised to determine what is valued within their particular fields and can also help provide the relevant habitus and transfer the relevant capitals to their children, to essentially ensure that the current situation and/or family advantage is maintained (Bourdieu 1984). Such perspectives imply that children's aspirations could be implicitly constrained, such as through science being considered as "not for people like me" via habitus (and/or someone's perceptions of the norms/expectations of the field of science), and explicitly constrained through children having limited capital in general (and/or having forms of capital that may not be valued within the field of science). Research has indeed highlighted that science aspirations and science education can be less accessible to children with lower levels of particular capitals, dispositions, and/or attitudes concerning science (e.g. Archer et al. 2015a, b; Wong, 2016). Additionally, science education has been criticised as perhaps having been historically focused on the professional development of scientists, where particular habitus/ views, personal characteristics, and/or capitals may be valued (potentially those endorsed or embodied by contemporary scientists), which may limit accessibility for those with differing views and/or for those who are not already represented within science (Claussen and Osborne 2013; Osborne and Dillon 2008).

Motivational and/or psychological perspectives, such as the social-cognitive theory proposed by Albert Bandura (e.g. Bandura 1986, 1989, 1997), suggest that personal agency and/ or particular beliefs such as someone's self-confidence remain important within life, but that these beliefs can be facilitated or constrained by various experiences, contexts, and other people (Bandura 1997). For example, the expectancy-value model of educational/career choices within social-cognitive theory (Eccles 2009; Wigfield and Eccles 2000) highlights the importance of someone's self-confidence, their interest in particular fields, and various other attitudes and beliefs, as important influences on their aspirations and their actual choices towards specific careers, while recognising that these are also influenced by prior experiences, contexts, and wider socio-cultural norms, expectations, and other factors (Eccles 2009). Such perspectives raise similar insights to sociological perspectives, but help clarify the potential relevance of particular attitudes and beliefs. Research has indeed found close associations between children's aspirations and their self-confidence in science and other views, as 
conceptualised within the expectancy-value model of social-cognitive theory (Bøe and Henriksen 2015).

Recent movements have combined aspects from across different perspectives. Specifically, the idea of science capital (somewhat following from sociological ideas of capital) encompasses multiple dimensions that include someone's self-confidence in feeling that they know about science, thinking that science is useful and relevant for careers, having parents who work in science and/or who find science interesting, engaging in extra-curricular science-related activities, and being encouraged to study science (Archer et al. 2015a; DeWitt et al. 2016; Godec et al. 2017). Essentially, science capital aimed to collate dimensions that associate with personal identification with and aspirations towards science, and combines aspects that might otherwise be conceptualised as distinct motivational attitudes or beliefs (within someone's habitus and/or within an expectancy-value model of social-cognitive theory) and/or as distinct forms of social capital or family capital that reflect aspects of available resources, networks, and/or support and encouragement (Archer et al. 2015a). These ideas broadly highlight the relevance of science-specific aspects of family backgrounds and also children's views.

Overall, these different perspectives broadly help to consider how children's circumstances may limit or foster their aspirations and/or how agency may be constrained. Some form of general family advantage, such as parents having higher socio-economic status, may be beneficial to children's aspirations; science-specific aspects of family life may be particularly relevant to children's science-related aspirations; and children's agency and their own attitudes and beliefs, such as their self-confidence, remain relevant but potentially constrained and/or influenced by their circumstances.

\section{Research Aims and Rationale}

It remains important to identify which children express aspirations towards science careers (or towards other areas), and how these views may change over time, given that relatively few longitudinal studies have been undertaken into the area (e.g. DeWitt et al. 2014; Sheldrake et al. 2017). It also remains important to consider whether children with different aspirations have different personal views, personal characteristics, and/or family backgrounds, including science-specific aspects, such as having parents working within science or not (e.g. Archer et al. 2015a). Increased understanding could suggest where support, encouragement, and/or interventions can be focused, such as to help support any children who may be more likely to change aspirations towards or away from science.

The presented research aimed to explore these areas through analysing the Millennium Cohort Study: this encompasses a nationally representative sample of children and their families from across the UK (encompassing the countries of England, Wales, Scotland, and Northern Ireland) (Fitzsimons et al. 2017; Ipsos MORI 2017), which facilitated considering children's views and their family backgrounds. The analysis focused on children from England, given that different educational contexts are present within each country and for increased comparability against prior research studies (which have mostly occurred within one country, such as England rather than across the entire UK).

The Millennium Cohort Study surveyed children and/or their families when the children were aged 9 months in 2001, aged 3 in 2004, aged 5 in 2006, aged 7 in 2008, aged 11 in 2012, and (most recently) aged 14 in 2015 (Fitzsimons et al. 2017). The analysis focused on the age 11 and age 14 surveys in order to explore changes in science-related aspirations during the initial years of secondary school and to facilitate comparability with prior studies. 
Overall, the aims of this study were to consider the longitudinal sample of children in England from the Millennium Cohort Study and hence to: (1) identify which children aspired towards science-related careers and how these aspirations changed from age 11 to age 14 and (2) reveal whether children with unchanged or changing aspirations had similar or different family backgrounds, personal characteristics, and/or personal views.

\section{Methods}

\section{Sample}

The Millennium Cohort Study encompasses a nationally representative sample of children and their families. In England, the initial sample consisted of 11,695 children who were born between the start of September 2000 and the end of August 2001 (Fitzsimons et al. 2017). In the latest 2015 survey, 7820 of these children in England responded (then aged 14); applying the latest sample-weighting during analysis accounted for this attrition in order to ensure that any results still generalise to the wider national population (Fitzsimons et al. 2017).

\section{Measurement}

When the children were aged 11 and aged 14, the children and their parents/guardians each completed their own questionnaires (Fitzsimons et al. 2017; Ipsos MORI 2017). In order to explicitly explore changes over time, the analysis focused on areas that were consistently measured at both age 11 and age 14, together with indicators of the children's personal characteristics and their family background. A large array of other indicators have been surveyed or measured (Ipsos MORI 2017), which remained outside of the scope of the presented research.

\section{Science-Related Career Aspirations and Occupations}

At age 11 and age 14, children expressed their aspirations through answering "When you grow up what would you like to be?" on the children's questionnaire; the children provided written free-text responses, which were coded by the survey organisers into "Standard Occupational Classification 2010" (SOC2010) codes (Fitzsimons et al. 2017; Office for National Statistics 2010a). Concurrently, their parents' and/or guardians' current occupations were similarly collected at these two times, via the parental/guardian questionnaires.

"Science-related" aspirations and occupations can be defined in various ways (Bosworth et al. 2013; Royal Society 2006, 2008a). For direct comparability with other national/ international research, this study applied the definition from the Organisation for Economic Co-operation and Development (OECD) (OECD 2016).

Science-related aspirations and occupations were accordingly defined as encompassing science/engineering, medicine/health, and information/technology professionals and technicians (OECD 2016, pp. 282-283). More specifically, within science/engineering, the definition included natural/physical scientists (across biology, chemistry, and physics, including astronomers and geologists/geophysicists), engineers (including civil, mechanical, electrical, and electronics engineers), and also conservation/environmental and architectural professionals; within medicine/health, the definition included doctors, dentists, veterinarians, nurses, and 
various specialists, but excluded psychologists and therapists (OECD 2016, pp. 282-283). Social scientists, sociologists, social workers, production/functional managers, and teaching professionals were excluded from the definition (OECD 2016, pp. 282-283). Production/ functional managers and teaching professionals have sometimes been historically considered to be science-related (Bosworth et al. 2013), although these occupations could conceivably focus on managing/teaching areas other than science.

Not every child and/or parent/guardian responded to the relevant questions at both times, however. In order to consistently consider all 7820 children, the aspirations/occupations were coded as either "science-related" or "not science-related, missing, and/or unknown," which again reflected the OECD approach (OECD 2016, p. 447). Preliminary analysis highlighted that the same findings emerged regardless of whether the coding excluded any cases with missing/unknown responses.

\section{Children's Family Background}

As of the children being aged 11 and aged 14, the highest level of parental/guardian education was measured via "National Vocational Qualification" levels (i.e. the highest level across the two parents/guardians who responded when their child was aged 11, then considered again for the highest level across the two parents/guardians who responded when their child was aged 14). The levels reflect (0) "no relevant qualifications," (1) "GCSEs or equivalents below grade C," (2) "GCSEs or equivalents at grades A-C," (3) "A-levels or equivalents," (4) "first university degrees or equivalent diplomas," and (5) "higher (post-graduate) degrees or equivalent diplomas." In England, GCSE (general certificate of secondary education) or equivalent secondary school qualifications are taken around age 15/16 (year 11), after which education is non-compulsory; A-level (advanced level general certificate of education) or equivalent uppersecondary school qualifications are taken around age 17/18 (year 13).

Similarly, as of the children being aged 11 and aged 14, the highest level of parental/ guardian socio-economic status (across the two parents/guardians who responded at that time point) was measured via the "National Statistics Socio-economic Classification" (NS-SEC) scheme, which considers someone's occupation and employment status, managerial responsibilities, and workplace size (Rose and O'Reilly 1998; Rose et al. 2005). The socio-economic status indicators broadly reflect (1) "routine occupations," (2) "semiroutine occupations," (3) "lower supervisory and technical occupations," (4) "small employers and own account workers," (5) "intermediate occupations," (6) "lower managerial, administrative, and professional occupations," and (7) "higher managerial, administrative, and professional occupations" (Rose et al. 2005; Office for National Statistics 2010b). Such labels are only illustrative: two people with the same occupation could be classified with different statuses, for example depending on having less/more managerial responsibilities and/or working in smaller/larger organisations (Office for National Statistics 2010b).

\section{Children's Characteristics}

The children's age (in month as of the start of 2015), gender, and ethnicity were considered, as of the age 14 questionnaire (i.e. the latest responses as of 2015). Preliminary analysis highlighted that there were no differences in reported gender from age 11 to age 14 and minimal differences in reported ethnicity (only 56 out of 7820 children reported 
differently). Given the minimal number of cases, considering the implications of any changes in ethnicity over time remained outside of the research aims (e.g. this might follow from changing self-identification, selecting options by mistake, selecting options to mislead the survey organisers, etc.); for brevity and efficiency, the latest age 14 indicators were analysed.

\section{Children's Views}

At age 11 and age 14, the children's questionnaire measured plausible influences on their career aspirations, although only a limited number of areas were consistently measured at both times.

Specifically, children expressed their self-confidence through disagreeing or agreeing with "I am good at English," "I am good at Maths," and "I am good at Science," via response categories of (1) "strongly disagree," (2) “disagree," (3) "agree," and (4) "strongly agree." Self-confidence measured in this way is sometimes referred to as subject-specific or domainspecific "self-concept beliefs" (Bong and Skaalvik 2003). Self-confidence is theorised to be a motivational influence (together with other influences) on children's aspirations and actions (Eccles 2009); self-confidence in science is also considered to be an aspect of children's science capital (Archer et al. 2015a; Godec et al. 2017).

Children also expressed their experiences and motivation towards their education across multiple questions ("How often do you try your best at school?," "How often do you find school interesting?," "How often do you feel unhappy at school?," "How often do you get tired at school?," and "How often do you feel school is a waste of time?") via response categories of (1) "never," (2) "some of the time," (3) "most of the time," and (4) "all of the time." Confirmatory factor analysis (via maximum-likelihood estimation) was undertaken as part of the analytical approach/preparation, and this highlighted that these items could be aggregated into a single measure of the children's school motivation and acceptable reliability was observed at age 11 (Cronbach's alpha $=0.707$ ) and age 14 (Cronbach's alpha $=0.699$ ). The responses/categories were re-coded as necessary, so that higher response values consistently reflected positive views/experiences (e.g. for "How often do you feel unhappy at school?" the response categories were re-coded as (1) "all of the time" to (4) "never"), and the average was calculated across the items to provide a single indicator.

Children also expressed their self-esteem (Rosenberg 1965) through disagreeing or agreeing with multiple statements ("On the whole, I am satisfied with myself," "I feel that I have a number of good qualities," "I am able to do things as well as most other people," "I am a person of value," and "I feel good about myself"), via response categories of (1) "strongly disagree," (2) "disagree," (3) "agree," and (4) "strongly agree." Factor analysis undertaken as part of the analytical approach/preparation highlighted that these items could be aggregated together, and acceptable reliability was observed at age $11($ Cronbach's alpha $=0.741)$ and age 14 (Cronbach's alpha $=0.905)$. The responses/categories were coded so that higher values consistently reflected positive self-esteem, and the average was calculated across the items to provide a single indicator.

Self-confidence, school motivation, and self-esteem broadly reflect potential personal and/ or contextual influences on aspirations, which could be conceptualised as direct and/or indirect influences within the expectancy-value or other theoretical models (e.g. Eccles 2009). Additionally, they provide potentially informative indicators in themselves. 


\section{Changes and Groups}

"Change-scores" were calculated from the various measures that approximated linear/ordinal scales (e.g. change in science self-confidence = age 14 science self-confidence - age 11 science self-confidence), where a positive value reflected an increase over time and a negative value reflected a decrease.

For the children's science-related career aspirations (binary/dichotomous indicators where calculating a change-score was not feasible), groups were formed through cross-tabulating the age 11 and age 14 "science-related" (called "yes" for brevity) and "not science-related, missing, and/or unknown" (called "no" for brevity) categories. Specifically, this identified children with science-related career aspirations as changing or remaining as "no to no," "yes to no," "no to yes," and "yes to yes" from age 11 to age 14 .

Equivalent cross-tabulations were also formed for the parents'/guardians' science-related occupations (binary/dichotomous indicators where change-scores were also not suitable), which revealed parents/guardians who moved into or out of science-related occupations.

\section{Analytical Approaches}

The Millennium Cohort Study initially sampled children/families within "clusters" (geographical census/electoral districts) within "strata" (with "advantaged," "disadvantaged," and "ethnic minority" strata), and attrition has also occurred over time (Fitzsimons et al. 2017). In order to ensure that the remaining sample was still representative of the intended original population, the latest sample-weighting (accounting for attrition) was applied across the analysis, via "complex samples" software functionality (Jones and Ketende 2010). The "complex samples" functionality also accounted for the stratified/clustered sampling design, which essentially mitigated the slight risk of "false positive" results that might otherwise occur (Jones and Ketende 2010).

Essentially, the original sample encompassed slightly different proportions of children from different backgrounds compared to what would be observed in the population, due to disadvantaged and ethnic minority children being over-sampled within the original sampling design; additionally, children/families from different clusters/strata may have had different levels of attrition over time (Ipsos MORI 2017). After applying the latest sampling-weights, this gave a sample-weighted or "representative sample" of 7718 children within the analytical approaches (i.e. each of the actual 7820 children in the sample was weighted to reflect anywhere from 0.1 to 11.0 representative children), which embodied the "correct" population-level proportions (while also accounting for any differences due to attrition). For comprehensiveness, the result tables show both the unweighted numbers and the sample-weighted numbers of children (i.e. highlighting that the groups were sufficiently large to ensure robust means and across-group comparisons regardless of sample-weighting), but only the sample-weighted group-size percentages are reported in the text (e.g. the group of children with consistent science-related career aspirations was $8.6 \%$ of the sample-weighted "representative sample," which can be inferred to be the percentage that would be seen in the wider population). The other results (such as means and standard deviations) and the statistical tests are consistently sample-weighted in order to provide similar insight onto the wider population.

Many statistical approaches only consider the particular cases (children) for which information (responses) is available. Considering fewer cases reduces the power of statistical tests to reveal significant differences, and in a longitudinal design, it is beneficial to consistently consider the same children. Accordingly, estimates of missing responses/values were produced 
using expectation-maximisation, which is considered one of the best contemporary approaches to handling missing data (IBM 2014; Peugh and Enders 2004). Essentially, all of the considered indicators were used as input, and any missing information was filled by estimates, given the other available information for that particular child and given the wider associations between indicators within the sample. The presented results include estimates of missing responses/values to ensure that all 7820 children were consistently analysed, regardless of the type of analysis and/or the indicators being considered. Preliminary analysis highlighted that the same results/conclusions emerged regardless of whether missing responses/values were estimated or not; the results from the analysis without estimating any missing responses/ values are appended within the Supplementary material for reference.

Similarities and differences were considered across the groups of children with sciencerelated aspirations that changed or remained "no to no," "yes to no," "no to yes," and "yes to yes," via analysis of variance tests undertaken via general linear models with "complex samples" sample-weighting. The tabulated results report the (sample-weighted) means and standard deviations per group, whether these means differed across the groups (seen through the statistical significance ( $p$ values) of the analysis of variance tests), and the magnitude of the difference across the groups (seen through the $R^{2}$ values). Statistical significance was indicated through the standard criterion $(p<0.05)$. The $R^{2}$ values reflect the proportion of variance in an indicator that can be attributed to the difference across the groups (for example, $R^{2}=0.041$ reflects an indicator varying by $4.1 \%$ across the groups). $R^{2}$ values are commonly interpreted with values above 0.02 reflecting a small difference, above 0.13 reflecting a moderate/medium difference, and above 0.26 reflecting a large difference (Cohen 1988). Values below a threshold for a small difference can be considered as minimal (or potentially trivial).

Multiple paired-comparison tests were also undertaken to consider differences across all of the potential pairs of groups (seen through the statistical significance ( $p$ values) of Bonferroni post hoc tests following the analysis of variance). For further clarity, the magnitudes of the differences in means across the pairs of groups are shown through Cohen's $D$ values. Cohen's $D$ values are comparable across different indicators (regardless of the original scale units) and are commonly interpreted with values above 0.20 reflecting a small difference, above 0.50 reflecting a moderate/medium difference, and above 0.80 reflecting a large difference (Cohen 1988).

\section{Results}

\section{Sample Summary}

On average across the children in England surveyed by the Millennium Cohort Study (Table 1), $20.8 \%$ expressed science-related career aspirations at age 11, while $24.3 \%$ expressed science-related career aspirations at age 14; the other children expressed aspirations towards other careers or did not answer the questions.

Only $9.1 \%$ of all children at age 11 and $10.4 \%$ at age 14 had parents/guardians working within science-related occupations (Table 1). Considering changes over time (not tabulated for brevity): only $6.5 \%$ of children had parents consistently working in science-related occupations, while $87.0 \%$ of children had parents consistently working in other fields; $3.9 \%$ of children had parents moving into science-related occupations, while $2.6 \%$ of children had 
Table 1 Summary of children's aspirations and views

\begin{tabular}{|c|c|c|c|c|c|c|}
\hline \multirow[t]{2}{*}{ Indicator (scale units) } & \multicolumn{2}{|l|}{ Age 11} & \multicolumn{2}{|l|}{ Age 14} & \multicolumn{2}{|c|}{ Difference over time } \\
\hline & $M$ & SD & $M$ & SD & Sig. $(p)$ & $D$ \\
\hline Children's science aspirations ( $1=$ yes $)$ & .21 & .41 & .24 & .43 & $<.001$ & .085 \\
\hline Either parent working in science $(1=$ yes $)$ & .09 & .29 & .10 & .31 & $<.001$ & .043 \\
\hline Highest parental SES (1-7) & 4.45 & 1.80 & 4.50 & 1.84 & .010 & .025 \\
\hline Highest parental education $(0-5)$ & 2.91 & 1.47 & 2.96 & 1.48 & $<.001$ & .029 \\
\hline Age (months, as of $1 / 1 / 2015$ ) & 166.48 & 3.50 & 166.48 & 3.50 & N/A & N/A \\
\hline Gender $(1=$ boy $)$ & .53 & .50 & .53 & .50 & N/A & N/A \\
\hline Ethnicity $(1=$ white $)$ & .74 & .44 & .74 & .44 & N/A & N/A \\
\hline Ethnicity $(1=$ mixed $)$ & .06 & .23 & .06 & .23 & N/A & N/A \\
\hline Ethnicity (1 = Indian) & .02 & .16 & .02 & .16 & N/A & N/A \\
\hline Ethnicity ( 1 = Pakistani) & .04 & .19 & .04 & .19 & $\mathrm{~N} / \mathrm{A}$ & N/A \\
\hline Ethnicity (1 = Bangladeshi) & .02 & .12 & .02 & .12 & N/A & N/A \\
\hline Ethnicity ( 1 = black Caribbean) & .02 & .12 & .02 & .12 & N/A & N/A \\
\hline Ethnicity (1 = black African) & .03 & .16 & .03 & .16 & N/A & N/A \\
\hline Ethnicity (1 = other) & .03 & .17 & .03 & .17 & N/A & N/A \\
\hline Ethnicity (1 = unknown) & .05 & .22 & .05 & .22 & $\mathrm{~N} / \mathrm{A}$ & N/A \\
\hline Self-confidence, English (1-4) & 3.06 & .68 & 2.98 & .70 & $<.001$ & .119 \\
\hline Self-confidence, mathematics $(1-4)$ & 3.28 & .72 & 2.99 & .78 & $<.001$ & .375 \\
\hline Self-confidence, science $(1-4)$ & 3.00 & .73 & 2.97 & .77 & .006 & .045 \\
\hline School motivation $(1-4)$ & 3.18 & .47 & 2.91 & .49 & $<.001$ & .561 \\
\hline Self-esteem $(1-4)$ & 3.36 & .43 & 3.09 & .57 & $<.001$ & .541 \\
\hline Number/percentage (unweighted) & 7820 & $100.0 \%$ & 7820 & $100.0 \%$ & & \\
\hline Number/percentage (weighted) & 7718 & $100.0 \%$ & 7718 & $100.0 \%$ & & \\
\hline
\end{tabular}

Notes: Sample-weighted statistics are reported: means $(M)$, standard deviations $(S D)$, statistical significance ('Sig. $(p)$ '; $p$ value) of the difference over time, and the magnitude (' $D$ '; Cohen's $D$ ) of the difference over time. Significant $p$ values $(p<0.05)$ are highlighted in bold for clarity. Missing responses were estimated by expectation-maximisation

parents who moved out of science-related occupations (such percentages sum to $100 \%$ and reflect the different possible categories of change or continuity).

Additionally (not tabulated for brevity): $61.0 \%$ of children had parents/guardians with unchanging socio-economic statuses, $20.1 \%$ of children had parents/guardians with increasing status, and $19.0 \%$ of children had parents/guardians with decreasing status. Concurrently, $86.0 \%$ of children had parents/guardians with unchanging levels of education, $8.6 \%$ of children had parents/guardians with increasing levels, and 5.4\% of children had parents/guardians with decreasing levels. It is plausible that the parents'/guardians' employment and education may have changed, but also plausible that different parents/guardians (and/or their different partners) may have completed the questionnaires at different times. For example, decreasing "highest levels of education" cannot easily be explained, other than by different parents, guardians, and/ or partners completing the questionnaires (or by people selecting/providing responses by mistake or for other reasons). Nevertheless, such results suggest that some children may experience changing family contexts and hence potentially changing influences over time.

\section{Characterising Changes or Continuity in Children's Science-Related Aspirations from Age 11 to Age 14}

Overall extents of change, on average across the entire cohort from age 11 to age 14, were mostly minimal in magnitude, except for a small magnitude of change for mathematics 
self-confidence and moderate/medium magnitudes of change for school motivation and for self-esteem (via Cohen's $D$ values; Table 1). However, averages may mask that different students have different extents or types of change.

Grouping the children into those with changes or continuity in their science-related career aspirations highlighted that few children ( $8.6 \%$ of the cohort) consistently expressed sciencerelated career aspirations at age 11 and at age 14, while the majority consistently expressed aspirations towards other occupations (63.5\%); however, more children changed their views towards science-related aspirations $(15.7 \%)$ than changed away from science-related aspirations $(12.2 \%)$ (these percentages sum to $100 \%$ and reflect the different possible categories of change or continuity, i.e. the different group sizes; Table 2).

\section{Family Background}

The children's family backgrounds are summarised in Table 2. Considering the children's parents/guardians, at age 11 and at age 14, the groups of children differed (on average) in the proportion of parents/guardians working within science-related occupations, level of occupational socio-economic status of their parents/guardians, and level of education of their parents/guardians, although the magnitudes of the differences across all the groups (via the $R^{2}$ values) were minimal (Table 2). The indicators of changes in family backgrounds (parents/guardians changing away/into working in science, having changing levels of socio-economic status, and having changing levels of education) did not differ across the groups except for differences, on average, in the proportion of parents/guardians moving into science-related occupations (Table 2).

The presence of differences across all of the groups (considered together) may be harder to observe (seen via the statistical significance), and the magnitudes of these differences may be lower (seen via the $R^{2}$ values), if differences only occur across some pairs of groups but not others. Accordingly, the paired-comparisons between groups (Table 3) provide particular insight in order to describe and potentially understand changes or continuity of aspirations.

Children Holding Consistent Aspirations Towards Science-Related Careers or Towards Other Areas At age 11 and at age 14, the children with consistent aspirations towards science-related careers (the "yes to yes" group) had higher proportions of parents/ guardians working in science, higher parental/guardian socio-economic status, and higher levels of parental/guardian education, than those children with consistent aspirations towards other areas (the "no to no" group) (Table 3). The magnitudes of these differences were small (seen via the Cohen's $D$ values), except for the minimal difference (below the threshold for a small difference) in parents/guardians working in science when the children were aged 11. The "yes to yes" group had more parents/guardians moving into sciencerelated occupations than the "no to no" group; however, these groups had similar proportions of parents/guardians moving away from science-related occupations, changing in socio-economic status, and changing in education (Table 3).

Children Moving Away from Compared to Moving Towards Science-Related Careers The children in the "yes to no" and "no to yes" groups did not differ for any of the family background indicators (or changing background indicators), at age 11 or at age 14 (Table 3). 


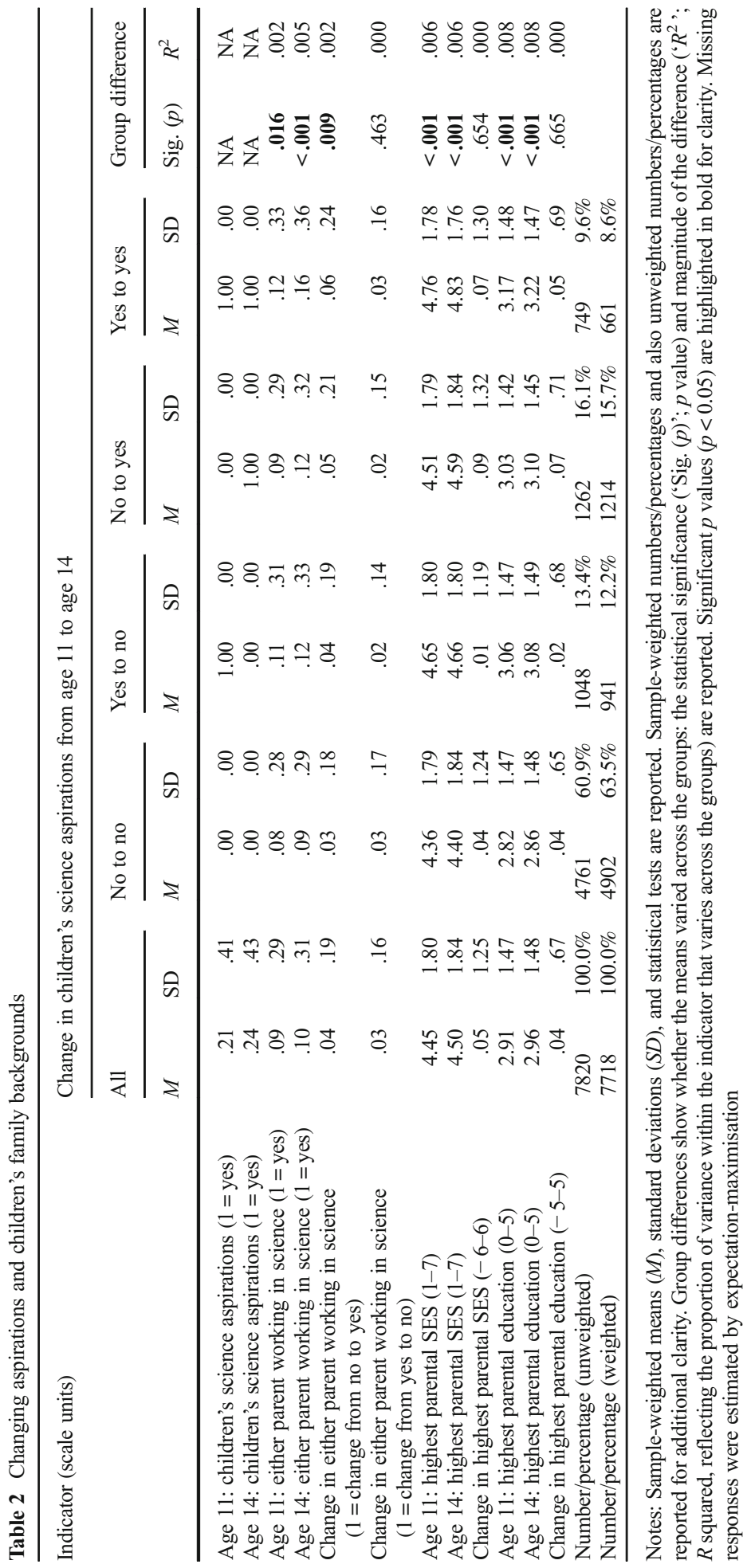


Table 3 Changing aspirations and children's family backgrounds (paired differences)

\begin{tabular}{|c|c|c|c|c|c|c|c|c|c|c|c|c|}
\hline \multirow[t]{2}{*}{ Indicator } & \multicolumn{2}{|c|}{ NN\&YN } & \multicolumn{2}{|c|}{ NN\&NY } & \multicolumn{2}{|c|}{ NN\&YY } & \multicolumn{2}{|c|}{ YN\&NY } & \multicolumn{2}{|c|}{ YN\&YY } & \multicolumn{2}{|c|}{ NY\&YY } \\
\hline & $D$ & $\begin{array}{l}\text { Sig. } \\
(p)\end{array}$ & $D$ & $\begin{array}{l}\text { Sig. } \\
(p)\end{array}$ & $D$ & $\begin{array}{l}\text { Sig. } \\
(p)\end{array}$ & $D$ & $\begin{array}{l}\text { Sig. } \\
(p)\end{array}$ & $D$ & $\begin{array}{l}\text { Sig. } \\
(p)\end{array}$ & $D$ & $\begin{array}{l}\text { Sig. } \\
(p)\end{array}$ \\
\hline $\begin{array}{l}\text { Age 11: either parent } \\
\text { working in science }\end{array}$ & .082 & .043 & .033 & .327 & .128 & .007 & .047 & .239 & .042 & .431 & .090 & .070 \\
\hline $\begin{array}{l}\text { Age 14: either parent } \\
\text { working in science }\end{array}$ & .112 & .003 & .094 & .005 & .222 & $<.001$ & .017 & .687 & .096 & .068 & .113 & .020 \\
\hline $\begin{array}{l}\text { Change in either parent } \\
\text { working in science } \\
\text { (from no to yes) }\end{array}$ & .016 & .659 & .065 & .077 & .144 & .002 & .046 & .288 & .116 & .024 & .068 & .140 \\
\hline $\begin{array}{l}\text { Change in either parent } \\
\text { working in science } \\
\text { (from yes to no) }\end{array}$ & .042 & .174 & .038 & .191 & .012 & .783 & .005 & .894 & .033 & .497 & .028 & .536 \\
\hline $\begin{array}{l}\text { Age 11: highest } \\
\text { parental SES }\end{array}$ & .164 & $<.001$ & .083 & .042 & .225 & $<.001$ & .081 & .157 & .061 & .301 & .142 & .013 \\
\hline $\begin{array}{c}\text { Age 14: highest } \\
\text { parental SES }\end{array}$ & .146 & .001 & .107 & .010 & .235 & $<.001$ & .039 & .479 & .092 & .120 & .129 & .013 \\
\hline $\begin{array}{l}\text { Change in highest } \\
\text { parental SES }\end{array}$ & .021 & .575 & .039 & .329 & .023 & .621 & .059 & .229 & .044 & .413 & .016 & .752 \\
\hline $\begin{array}{l}\text { Age 11: highest } \\
\text { parental education }\end{array}$ & .167 & $<.001$ & .148 & $<.001$ & .243 & $<.001$ & .020 & .738 & .076 & .297 & .098 & .124 \\
\hline $\begin{array}{l}\text { Age 14: highest } \\
\text { parental education }\end{array}$ & .152 & .002 & .163 & $<.001$ & .247 & $<.001$ & .011 & .841 & .095 & .163 & .086 & .158 \\
\hline $\begin{array}{l}\text { Change in highest } \\
\text { parental education }\end{array}$ & .030 & .509 & .040 & .416 & .015 & .752 & .066 & .219 & .043 & .420 & .023 & .654 \\
\hline
\end{tabular}

Notes: Sample-weighted statistics are reported: the magnitude (' $D$ '; Cohen's $D$ ) of the difference in means across the groups, and the statistical significance ('Sig. $(p)^{\prime} ; p$ value) from the Bonferroni paired difference tests. Significant $p$ values $(p<0.05)$ are highlighted in bold for clarity. The group are abbreviated as: 'No to No' (NN); 'Yes to No' (YN); 'No to Yes' (NY); and 'Yes to Yes' (YY); for example, the 'NN\&YN' results show the comparison between the 'No to No' and the 'Yes to No' groups. Missing responses were estimated by expectation-maximisation

\section{Children Moving Away Compared to Holding Consistent Aspirations Towards}

Science-Related Careers The children in the "yes to no" and the "yes to yes" groups only differed in the proportion of parents/guardians moving into science-related occupations (the children in the "yes to yes" group had a higher proportion of parents/guardians moving into science-related occupations) (Table 3).

\section{Children's Characteristics}

The children's personal characteristics are summarised in Table 4. The groups of children differed in gender and ethnicity proportions, on average, but did not differ in age measured in months (despite the Millennium Cohort Study covering children born across an entire year). The magnitudes of the overall differences across all of the groups (via the $R^{2}$ values) were minimal (Table 4); nevertheless, when considered across particular pairs of groups, the statistically significant gender differences were small (non-trivial) in magnitude (seen via the Cohen's $D$ values; Table 5). 


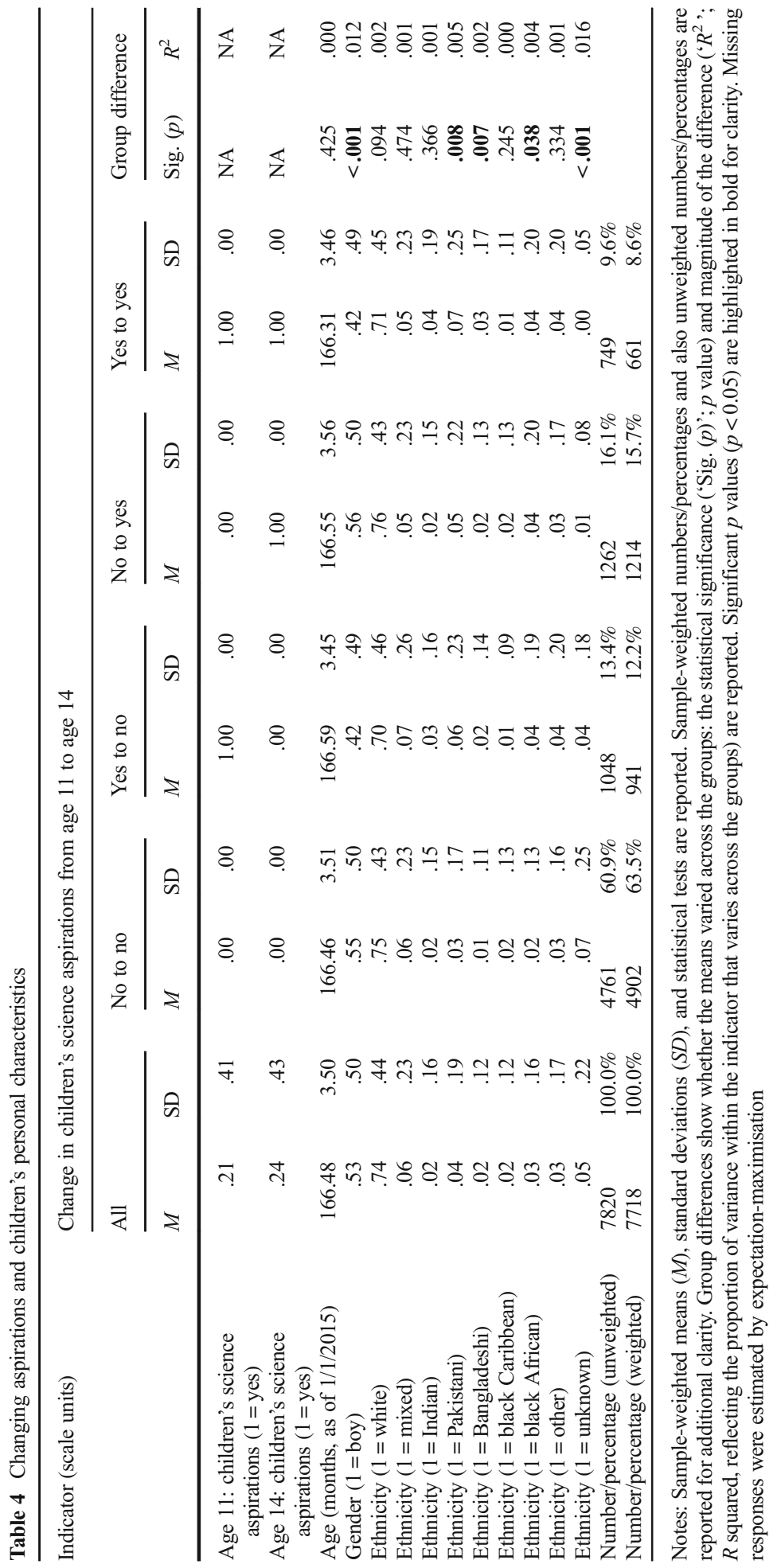


Table 5 Changing aspirations and children's personal characteristics (paired differences)

\begin{tabular}{|c|c|c|c|c|c|c|c|c|c|c|c|c|}
\hline \multirow[t]{2}{*}{ Indicator } & \multicolumn{2}{|c|}{$\mathrm{NN} \& \mathrm{YN}$} & \multicolumn{2}{|c|}{ NN\&NY } & \multicolumn{2}{|c|}{ NN\&YY } & \multicolumn{2}{|c|}{ YN\&NY } & \multicolumn{2}{|c|}{ YN\&YY } & \multicolumn{2}{|c|}{ NY\&YY } \\
\hline & $D$ & $\begin{array}{l}\text { Sig. } \\
(p)\end{array}$ & $D$ & $\begin{array}{l}\text { Sig. } \\
(p)\end{array}$ & $D$ & $\begin{array}{l}\text { Sig. } \\
(p)\end{array}$ & $D$ & $\begin{array}{l}\text { Sig. } \\
(p)\end{array}$ & $D$ & $\begin{array}{l}\text { Sig. } \\
(p)\end{array}$ & $D$ & $\begin{array}{l}\text { Sig. } \\
(p)\end{array}$ \\
\hline $\begin{array}{l}\text { Age (months, as of } \\
1 / 1 / 2015 \text { ) }\end{array}$ & .037 & .382 & .026 & .495 & .044 & .293 & .010 & .840 & .082 & .116 & .070 & .196 \\
\hline Gender (1 = boy) & .269 & $<.001$ & .008 & .826 & .260 & $<.001$ & .278 & $<.001$ & .009 & .861 & .268 & $<.001$ \\
\hline Ethnicity $(1=$ white $)$ & .101 & .049 & .032 & .465 & .080 & .150 & .133 & .031 & .020 & .731 & .113 & .057 \\
\hline Ethnicity $(1=$ mixed $)$ & .075 & .138 & .007 & .814 & .010 & .825 & .080 & .123 & .081 & .206 & .003 & .949 \\
\hline Ethnicity ( 1 = Indian) & .021 & .555 & .004 & .910 & .102 & .096 & .017 & .673 & .072 & .242 & .091 & .126 \\
\hline Ethnicity ( 1 = Pakistani) & .146 & .004 & .111 & .061 & .205 & .012 & .029 & .611 & .045 & .431 & .075 & .305 \\
\hline $\begin{array}{l}\text { Ethnicity }(1= \\
\text { Bangladeshi) }\end{array}$ & .072 & .008 & .042 & .179 & .146 & .015 & .027 & .401 & .058 & .241 & .086 & .081 \\
\hline $\begin{array}{l}\text { Ethnicity }(1=\text { black } \\
\text { Caribbean })\end{array}$ & .065 & .080 & .000 & .995 & .026 & .523 & .070 & .164 & .045 & .439 & .027 & .261 \\
\hline $\begin{array}{l}\text { Ethnicity }(1=\text { black } \\
\text { African })\end{array}$ & .123 & .141 & .155 & .065 & .149 & .040 & .028 & .753 & .019 & .830 & .010 & .889 \\
\hline Ethnicity ( $1=$ other $)$ & .079 & .184 & .015 & .704 & .100 & .080 & .059 & .236 & .017 & .709 & .078 & .137 \\
\hline $\begin{array}{l}\text { Ethnicity } \\
\qquad(1=\text { unknown })\end{array}$ & .141 & $<.001$ & .274 & $<.001$ & .281 & $<.001$ & .212 & $<.001$ & .226 & $<.001$ & .056 & .164 \\
\hline
\end{tabular}

Notes: Sample-weighted statistics are reported: the magnitude (' $D$ '; Cohen's $D$ ) of the difference in means across the groups, and the statistical significance ('Sig. $(p)^{\prime} ; p$ value) from the Bonferroni paired difference tests. Significant $p$ values $(p<0.05)$ are highlighted in bold for clarity. Missing responses were estimated by expectation-maximisation

Children Holding Consistent Aspirations Towards Science-Related Careers or Towards Other Areas The group of children with consistent aspirations towards science (the "yes to yes" group) encompassed lower proportions of boys, higher proportions of children from Pakistani, Bangladeshi, and black African backgrounds, and lower proportions of children from unknown backgrounds, than the group of children with consistent aspirations towards other areas (the "no to no" group) (Table 5). These differences were minimal in magnitude, except for small magnitudes of differences for gender, Pakistani backgrounds, and unknown backgrounds.

\section{Children Moving Away from Compared to Moving Towards Science-Related}

Careers The children in the "yes to no" and "no to yes" groups differed in gender proportions (the proportion of boys was lower in the "yes to no" group and higher in the "no to yes" group with a small magnitude of difference), differed in the proportions of those from white backgrounds (lower in the "yes to no" group and higher in the "no to yes" group but with a minimal magnitude of difference), and differed in the proportions of those from unknown backgrounds (higher in the "yes to no" group and lower in the "no to yes" group with a small magnitude of difference) (Table 5).

\section{Children Moving Away Compared to Holding Consistent Aspirations Towards}

Science-Related Careers The children in the "yes to no" and the "yes to yes" groups did not differ for these indicators of children's characteristics, except for higher proportions of children from unknown ethnic backgrounds being present in the "yes to no" group with a small magnitude of difference (Table 5). 


\section{Children's Views}

The children's personal views are summarised in Table 6. On average across the sample, the children's mathematics self-confidence, school motivation, and self-esteem decreased from age 11 to age 14, while their English self-confidence and science self-confidence showed minimal decreases. Regardless of such changes, on average, the children's responses remained positive at age 14 (i.e. close to 3 on the 1-4 scales). Additionally, even the groups of children with consistent career aspirations towards fields other than science (the "no to no" group) and with career aspirations moving away from science (the "yes to no" group) still expressed (on average) positive science self-confidence at age 14 .

Overall, the groups of children differed, on average at age 11 and age 14, in the magnitude of their English self-confidence, mathematics self-confidence, science selfconfidence, school motivation, and self-esteem; additionally, the groups differed in the extent of change in their science self-confidence, school motivation, and self-esteem (but did not differ in the extent of change in English self-confidence or mathematics selfconfidence) (Table 6). The magnitudes of these overall differences were minimal, except for a small magnitude of difference in science self-confidence at age 14 (via the $R^{2}$ values; Table 6); however, when considered across particular pairs of groups, some science selfconfidence and school motivation differences were small or moderate/medium in magnitude (via the Cohen's $D$ values; Table 7).

\section{Children Holding Consistent Aspirations Towards Science-Related Careers or To-} wards Other Areas The group of children with consistent aspirations towards science (the "yes to yes" group) reported higher at age 11 and at age 14 for their English selfconfidence, mathematics self-confidence, science self-confidence, school motivation, and self-esteem (excepting that self-esteem only differed at age 11 and not at age 14) than the group of children with consistent aspirations towards other areas (the "no to no" group) (Table 7). These differences were small in magnitude, except for minimal differences for English self-confidence and for self-esteem, and moderate/medium differences for science self-confidence at age 14. Additionally, these groups differed in the extent of change in their science self-confidence: those with consistent aspirations towards science exhibited a slight increase in science self-confidence, while those with consistent aspirations towards other areas exhibited a slight decrease in science self-confidence (Table 7).

\section{Children Moving Away from Compared to Moving Towards Science-Related}

Careers The children in the "yes to no" and "no to yes" groups had similar magnitudes of English self-confidence, mathematics self-confidence, science self-confidence, school motivation, and self-esteem at age 11 but different magnitudes at age 14 (except for still having similar English self-confidence at age 14), characterised by those in the "no to yes" group holding more positive views at age 14 compared to those in the "yes to no" group (Table 7). Accordingly, these groups had different extents of change in science self-confidence, school motivation, and self-esteem; the most notable difference was that the "yes to no" group decreased in science self-confidence while the "no to yes" group increased in science selfconfidence (Table 7). These differences at age 14 and the different extents of change were small in magnitude for science self-confidence and for school motivation, but otherwise were minimal in magnitude. 


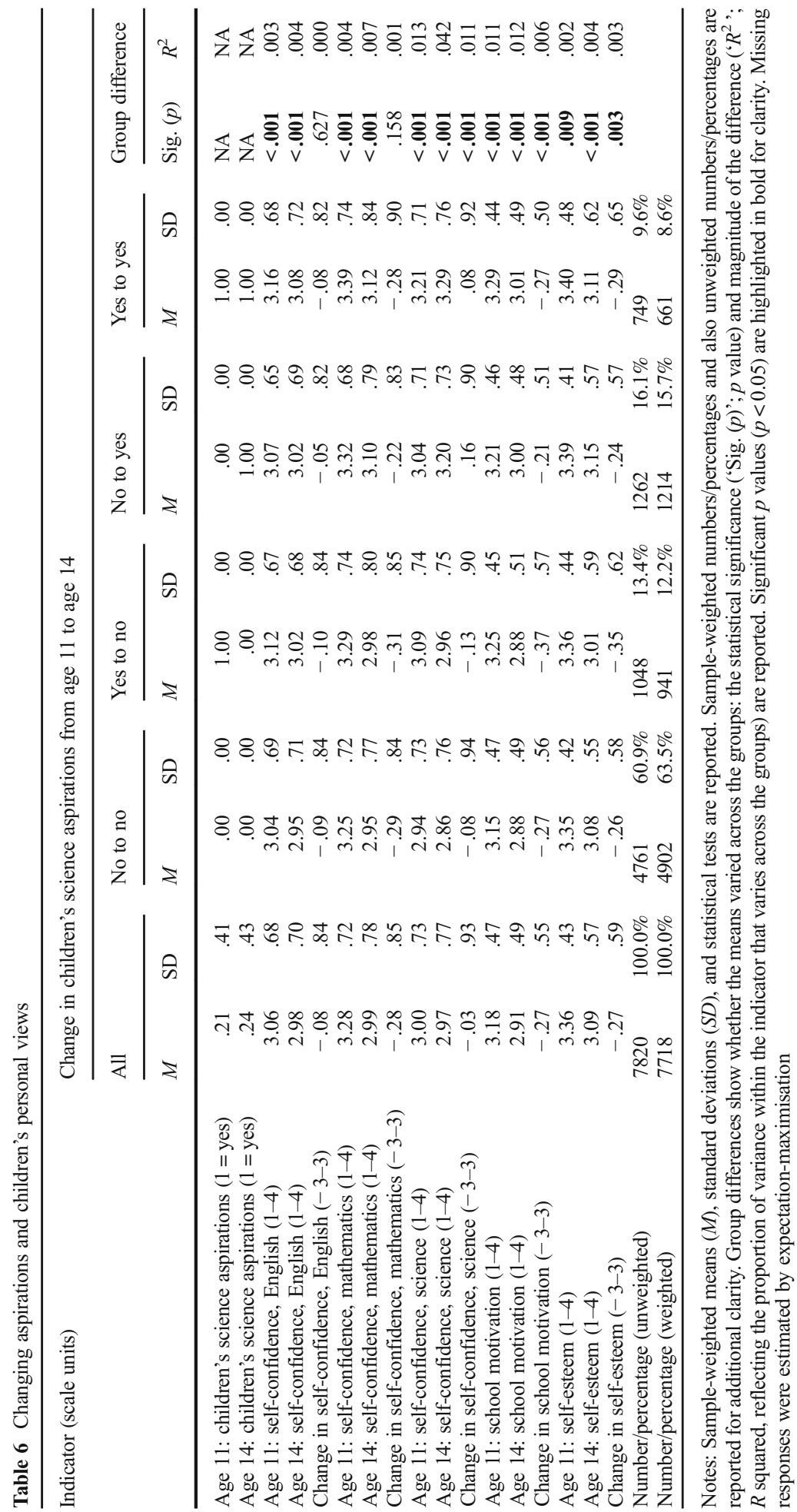




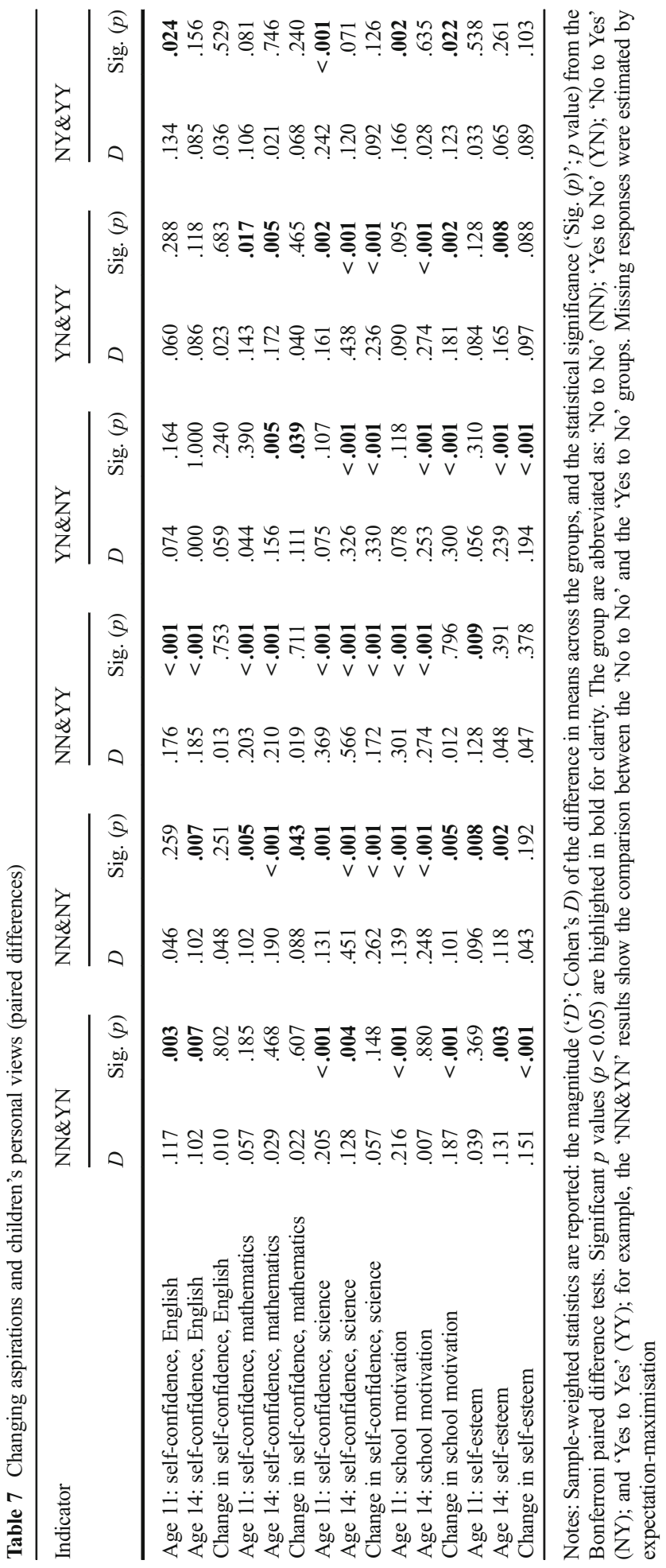




\section{Children Moving Away Compared to Holding Consistent Aspirations Towards}

Science-Related Careers At age 11 and age 14, the children in the "yes to no" and the "yes to yes" groups expressed similar English self-confidence but different mathematics selfconfidence and different science self-confidence (with those in the "yes to yes" group expressing higher views); these groups also expressed similar school motivation and selfesteem at age 11 but different magnitudes at age 14 (with those in the "yes to yes" group expressing higher views) (Table 7). The magnitudes of these differences were minimal, except for small differences in science self-confidence at age 14 (and for the extent of change in science self-confidence) and school motivation at age 14 (Table 7). These groups differed in the extents of change in their science self-confidence and change in their school motivation (Table 7): those who moved away from science-related aspirations (the "yes to no" group) exhibited a decrease in science self-confidence (while those in the "yes to yes" group exhibited an slight increase) and exhibited a greater decrease in their school motivation (while those in the "yes to yes" group exhibited a decrease in their school motivation but at a lesser extent).

\section{Discussion}

The various findings from this study provide new insights for science educators, researchers, sociologists, and wider stakeholders interested in children's science-related aspirations, social mobility, and/or the potential transmission of some form of advantage from parents to children. Children with consistent aspirations towards science-related careers were characterised by having the most advantaged family backgrounds at age 11 and at age 14, which raises concerns over science being potentially perceived as inaccessible for those with disadvantaged backgrounds (so that their aspirations may then focus towards other occupational fields); this also suggests that support to mitigate disadvantage may be beneficial before age 11. Children with changing aspirations away from or towards science-related careers between age 11 and age 14 were not characterised by differences in family backgrounds but were characterised by differences in children's personal characteristics and personal views (particularly their selfconfidence in science), which raises concerns over future diversity within science and highlights that support during secondary school may continue to be beneficial. Nevertheless, these differences were mostly minimal or small in magnitude.

The relatively low magnitudes of difference observed across the results implicitly highlight the need to explore wider areas of education and life in order to better understand children's changing career aspirations, perhaps through considering (for example) any norms and expectations that children may perceive within the fields of education and science. For example, while the findings suggest the benefit of supporting and fostering children's science self-confidence, which likely also requires supporting and fostering their underlying skills and knowledge in science, it may be equally important for educators and stakeholders to consider why science is perceived by many children as difficult, as needing "cleverness," and/or as potentially being more suited to some people but not others (Archer et al. 2015b, 2017).

\section{Findings, Contextualisation, and Implications}

The first research aim was to identify which children aspired towards science-related careers and how these aspirations changed from age 11 to age 14. On average across the nationally 
representative sample of children in England surveyed by the Millennium Cohort Study, $20.8 \%$ expressed science-related career aspirations at age 11 (surveyed in 2012), while $24.3 \%$ expressed science-related career aspirations at age 14 (surveyed in 2015). Few children (8.6\% of the cohort) consistently expressed science-related career aspirations at age 11 and again at age 14; more children (15.7\%) changed from expressing other (non-science) career aspirations at age 11 to express science-related career aspirations at age 14; other children $(12.2 \%)$ changed from expressing science-related career aspirations at age 11 to express other (non-science) career aspirations at age 14; and the remaining majority of children $(63.5 \%)$ consistently expressed career aspirations towards other (non-science) fields. Potentially problematically, cross-sectional statistics may mask that relatively few children appear to consistently aspire towards science-related careers across time; nevertheless, it is equally important to recognise that some children can change their aspirations towards science careers.

Prior studies have reported somewhat similar findings: from the children in England surveyed at age 15 by the Programme for International Student Assessment (PISA) in 2015, $29.7 \%$ expressed science-related career aspirations (OECD 2016, p. 447). Other studies in England have also highlighted increasing aspirations, for some but not all children, during early secondary school (DeWitt et al. 2014; Sheldrake et al. 2017). However, it remains unclear whether similar percentages of children would actually study (non-compulsory) science-related subjects at upper-secondary school (after age 16/17) and at university (after age 18/19), and ultimately work within science-related fields, given that some progression rates have appeared to be lower (depending on the subject) (EngineeringUK 2017; Gatsby 2017; Royal Society 2006). Further research into the varying frequencies or extents of changing career aspirations over time and/or other trajectories of change is likely to be beneficial.

The second research aim was to reveal whether children with unchanged or changing career aspirations had similar or different family backgrounds, personal characteristics, and/or personal views. Children who consistently expressed science-related career aspirations (compared to children who consistently expressed career aspirations towards other occupations) had more advantaged backgrounds (reflected through the level of occupational socio-economic status and the level of education of their parents/guardians, where there were small magnitudes of difference), higher self-confidence (with small to moderate/medium magnitudes of difference), and higher self-esteem (with a minimal magnitude of difference). These findings were broadly consistent with the implications from prior research into the generalised transmission of advantage from parents to children (which has linked higher family socio-economic status with young people entering professional careers including science-related careers, e.g. Macmillan et al. 2015) and from prior research specifically considering children's science aspirations (which has linked higher levels of family education and cultural capital with higher science capital which has linked with children's aspirations towards science, e.g. Archer et al. 2015a). This reaffirms concerns around the overall accessibility of science for those from disadvantaged backgrounds and highlights that children may benefit from support both before and after age 11, given that differences in family advantage/disadvantage were already apparent as of age 11 .

The children who consistently expressed science-related career aspirations also had higher proportions of parents working within science-related fields, compared to children who consistently expressed aspirations towards other occupations (although only at a minimal magnitude of difference at age 11 but at a small magnitude of difference at age 14). This is consistent with some families being potentially able to provide specific science capital, which 
is likely to be facilitated when parents work within science (Archer et al. 2015a; DeWitt et al. 2016). Additionally, more children from Pakistani and from Bangladeshi backgrounds consistently expressed science-related aspirations, which links with prior research highlighting that families from some ethnic backgrounds may have more science capital through parents holding positive views about science and/or science-related careers and encouraging sciencerelated aspirations in their children (Archer and Francis 2006; Archer et al. 2014). Nevertheless, future research may be beneficial into which aspects of science capital may be available or fostered in different families, and how much "advantage" may follow from family members explicitly working within science, holding positive attitudes towards science, and/or giving support and encouragement. Additionally, it remains unclear whether any particular aspect of family backgrounds (such as parents working within science) becomes especially relevant at particular ages or decision points, such as whether and/or how to apply to science-related courses at university.

More girls than boys consistently expressed science-related aspirations within the presented results. Prior research has, in contrast, often shown that girls hold lower aspirations towards physical science fields such as physics (Archer et al. 2010, 2017; Institute of Physics 2013). The presented results may have followed from the inclusive measure of "science-related" career aspirations, which encompassed aspirations towards science/engineering and also medicine/health and information/technology occupations. Further research may be beneficial in order to explore changes and continuity within more specific areas (such as medicine/health and/or the biological sciences) or even occupations (such as particular aspirations to become a doctor, nurse, physicist, biologist, or chemist) and any associated gender differences, in order to gain greater clarity and insight.

The children who changed aspirations towards or away from science-related careers were not characterised by any differences in the level of occupational socio-economic status and the level of education of their parents/guardians, or any differences in the extents of change in these indicators (a notable and new insight arising from this study). However, there were minimal changes in the overall levels of education and levels of socio-economic status of parents/guardians, which may have ensured that any consequences on children would be harder to observe; concurrently, consequences might occur over longer time periods and/or might occur indirectly rather than directly. Nevertheless, future research exploring transmission of advantage (including advantage such as parents working in science, and/or aspects of science capital) could perhaps benefit from further consideration of whether a change in family context entails a change in children's aspirations and/or other views.

Children who changed aspirations towards science-related careers (compared to children who changed aspirations away from science) were more likely to be boys (with a small magnitude of difference), children from white backgrounds (with a minimal magnitude of difference), and children with higher (at age 14) mathematics self-confidence, science selfconfidence, school motivation, and self-esteem (with minimal to small magnitudes of difference). This broadly supports existing concerns over increasing gender/ethnicity differences in science-related aspirations as children grow older and the associated risk of inequity in accessibility (e.g. Institute of Physics 2013).

Children who changed aspirations towards science-related careers were notably characterised by increasing science self-confidence, while those who changed aspirations away from science-related careers were characterised by decreasing science self-confidence (where the magnitude of the difference was small but non-trivial). These findings link with prior studies and theoretical perspectives that emphasise the importance of children's 
motivational beliefs such as their self-confidence (e.g. Bøe and Henriksen 2015; Eccles 2009). In prior research, decreasing self-confidence in science has been observed when children moved away from science during secondary school, together with the children having increasing or competing interests in other areas, less access to extra-curricular activities, and less school and/or family support (Aschbacher et al. 2010). Many other prior studies have associated children's science-related aspirations and/or studying choices with their science self-confidence, their interest in science, and how useful studying or working within science is considered to be, together with various other factors (e.g. DeWitt and Archer 2015; Mujtaba and Reiss 2014). On a wider level, future research may benefit from considering which proportions of children move away from science following from declining science selfconfidence (and/or other views), and which proportions of children move away from science following from developing interests or aspirations in other areas (while their science-related views might remain relatively high and/or unchanged). This would involve considering children's aspirations and views across many different fields (not just science) and considering many different attitudes, beliefs, and wider views (not just self-confidence). Additionally, and in accordance with implications from prior research, it perhaps remains important to reassure children that holding early aspirations and/or interests are not necessarily essential to studying and/or working within science-related areas (as many scientists have reported that their interests actually developed during secondary school; Maltese and Tai 2010; Venville et al. 2013), and educators may need to be mindful of recognising and supporting positive changes and developing children's aspirations.

Ultimately, the presented results suggest which children (on average) might benefit from encouragement and/or support: children who changed from non-science to science-related career aspirations were more likely to be boys and children from white backgrounds, compared to those who changed career aspirations away from science, which suggests that girls and nonwhite children may increasingly benefit from support. Additionally, it is plausible to infer that fostering self-confidence (which likely also involves fostering children's underlying skills and knowledge) may help some children to move back towards science. Nevertheless, educators and stakeholders may also need to consider and address wider aspects of education and life, such as whether and why science is perceived as difficult, as needing "cleverness," and/or as potentially being more suited to some people but not others (Archer et al. 2015b, 2017). Otherwise, actions to improve accessibility to science and/or mitigating any disadvantage following from children's backgrounds have to rely on supporting and encouraging children, while the fields of education and science (and any associated norms and expectations) implicitly remain unchanged or unquestioned.

\section{Limitations}

The presented research focused on revealing children with consistent or changing career aspirations towards science: essentially, the study focused on describing the situation in England through a large-scale and nationally representative sample. This provided new insights via clarifying proportions and extents of change and also provided the basis and groundwork for further research. However, this does not, in itself, explain why any changes in career aspirations actually occurred. Applying further research methods remains beneficial, such as interviewing students to explore their own accounts of their changing aspirations and influences.

The children surveyed by the Millennium Cohort Study are nationally representative (when sample-weighting is applied) of a specific population: children born between the start of 
September 2000 and the end of August 2001 as sampled through households and various geographical and other strata (Fitzsimons et al. 2017). It remains possible that different results may follow from different samples/populations (such as through randomly sampling children at particular ages via schools). Different results may also follow from different cohorts, due to continual changes in society, educational systems, and any number of aspects associated with living in a particular country at a particular time.

Considering the Millennium Cohort Study ensured that the analysis was unavoidably limited by the available data; for example, no indicators of children's science attainment are present within the publicly available data. Any number of other indicators or factors may associate with and/or help explain children's aspirations and/or changing aspirations, such as children's beliefs about fields of work being useful to their future lives (Bøe and Henriksen 2015). For the considered indicators in the presented results, the magnitudes of differences across the groups were often minimal, although some were small or moderate in magnitude, which implicitly highlighted that further factors may need to be considered in order to better characterise how the groups differed and/or to link with children's changing career aspirations.

The presented analysis also focused on specific indicators, given prior theory and research within science education and where indicators were measured at age 11 and also at age 14 . The Millennium Cohort Study questionnaires covered numerous others areas, including, for example at age 14, the children's time spent on leisure activities, some wider attitudes such as towards consumerism, their closeness and relations with family members including perceived support, some potentially problematic behaviours or experiences (including bullying, anti-social behaviour, and crime), and their self-perceptions of health (including healthy eating, sleeping, and experiencing puberty) (Fitzsimons et al. 2017). These nevertheless offer much scope for others researchers to explore (where the impacts of healthy eating, drinking alcohol, and/or sleep times might be explored in relation to self-perceptions of health, for example).

The analysis involved categorising children's career aspirations as science-related or not (given international definitions of science-related occupations; OECD 2016, pp. 282-283), which produced binary/dichotomous indicators. Many prior studies have considered students' aspirations through the extent of their agreement or disagreement towards intending to study more science in the future and/or towards following science careers (e.g. DeWitt and Archer 2015; Mujtaba and Reiss 2014). Different indicators may provide different insights, and future research may benefit from applying multiple measures. It may also be beneficial to explore and/or confirm what occupations are considered to be "science-related" by children.

Science-related occupations are often ranked relatively highly in socio-economic status, regardless of someone's employment status, managerial responsibilities, and workplace size (Rose and O'Reilly 1998; Rose et al. 2005); concurrently, science-related occupations may often require higher levels of education (Royal Society 2006, 2008a). Essentially, it may be difficult to clearly separate "working within a science field" and "higher status and/or education," given contemporary conceptualisations regarding socio-economic status. Considering such issues also raises questions about what, exactly, occupational "status" means and why some occupations are considered "higher" than others, and further critical consideration may be beneficial.

Sociological perspectives suggest that families working within specific areas/fields may have knowledge of the particular attitudes and/or actions that are valued within them and hence could convey these to their children (Bourdieu 1984). Further exploration of these ideas may be beneficial, which might involve the measurement of wider indicators potentially linked with science capital and/or someone's advantage/status in society. Concurrently, recognising 
children's agency remains important, given that children's aspirations and choices are strongly associated with their own attitudes and beliefs (Bøe and Henriksen 2015), and benefit may follow from exploring how children's agency, aspirations, and/or attitudes may be particularly facilitated or constrained in different situations or contexts.

\section{Conclusions}

Children who consistently expressed science-related career aspirations at age 11 and at age 14 had more advantaged backgrounds (reflected through the level of occupational socioeconomic status and the level of education of their parents/guardians), higher proportions of parents/guardians working within science-related fields, higher self-confidence, and higher self-esteem, compared to children who consistently did not express science-related career aspirations. Some support before and after age 11 may be beneficial to help ensure that children's career aspirations are not unnecessarily limited by family disadvantage.

Children who changed aspirations towards science-related careers (compared to those who changed aspirations away from science-related careers) were more likely to be boys, children from white backgrounds, and children with higher (at age 14) mathematics self-confidence, science self-confidence, school motivation, and self-esteem. Accordingly, support within secondary schools (and/or by wider stakeholders) may need to increasingly involve promoting the accessibility of science for all children, regardless of gender and ethnicity (some practical guidance is already available, e.g. Institute of Physics 2015). Children who changed aspirations towards science-related career aspirations were notably characterised by increasing science self-confidence, while those who changed aspirations away from science-related career aspirations were characterised by decreasing science self-confidence. Accordingly, benefits may arise from continuing to foster children's skills and knowledge in science; schools and stakeholders may also need to address any assumptions that science is only for those with "natural ability" or "clever" children, and that skills can be learnt and developed.

Overall, these findings help inform where support, encouragement, and/or interventions could plausibly be focused. These findings also link with prior studies and theoretical perspectives that emphasise the importance of children's motivational beliefs, such as their self-confidence (e.g. Bøe and Henriksen 2015; Eccles 2009). On a wider level, the findings broadly suggest that family advantage, including parents/guardians specifically working within science-related fields, may plausibly provide the potential for an initial fostering of aspirations, but that children's views such as their self-confidence may be increasingly relevant to their aspirations over time and/or for changes in aspirations. Nevertheless, further work remains necessary in order to clarify why particular changes in aspirations occur, and how children can be best supported.

Acknowledgements The presented research was conducted independently of the organisers of the Millennium Cohort Study.

Compliance with Ethical Standards The organisers of the Millennium Cohort Study have documented that they received approval from ethics committees before surveying, and that informed consent to participate has been gained from children and parents/guardians (Fitzsimons et al. 2017; Ipsos MORI 2017). The anonymous Millennium Cohort Study data (with no personally-identifying data) are publicly-available through the UK Data Service (Fitzsimons et al. 2017).

Conflict of Interest The author declares that there is no conflict of interest. 
Open Access This article is distributed under the terms of the Creative Commons Attribution 4.0 International License (http://creativecommons.org/licenses/by/4.0/), which permits unrestricted use, distribution, and reproduction in any medium, provided you give appropriate credit to the original author(s) and the source, provide a link to the Creative Commons license, and indicate if changes were made.

\section{References}

ACOLA. (2013). STEM: country comparisons: international comparisons of science, technology, engineering and mathematics (STEM) education. Melbourne: Australian Council of Learned Academies.

ACOLA. (2014). The role of science, research and technology in lifting Australian productivity. Melbourne: Australian Council of Learned Academies.

Archer, L., \& Francis, B. (2006). Challenging classes? Exploring the role of social class within the identities and achievement of British Chinese pupils. Sociology, 40(1), 29-49. https://doi.org/10.1177 $/ 0038038506058434$.

Archer, L., DeWitt, J., Osborne, J., Dillon, J., Willis, B., \& Wong, B. (2010). “Doing” science versus "being” a scientist: examining 10/11-year-old schoolchildren's constructions of science through the lens of identity. Science Education, 94(4), 617-639. https://doi.org/10.1002/sce.20399.

Archer, L., DeWitt, J., Osborne, J., Dillon, J., Willis, B., \& Wong, B. (2012). Science aspirations, capital, and family habitus: how families shape children's engagement and identification with science. American Educational Research Journal, 49(5), 881-908. https://doi.org/10.3102/0002831211433290.

Archer, L., DeWitt, J., \& Wong, B. (2014). Spheres of influence: what shapes young people's aspirations at age $12 / 13$ and what are the implications for education policy? Journal of Education Policy, 29(1), 58-85. https://doi.org/10.1080/02680939.2013.790079.

Archer, L., Dawson, E., DeWitt, J., Seakins, A., \& Wong, B. (2015a). "Science capital": a conceptual, methodological, and empirical argument for extending Bourdieusian notions of capital beyond the arts. Journal of Research in Science Teaching, 52(7), 922-948. https://doi.org/10.1002/tea.21227.

Archer, L., DeWitt, J., \& Osborne, J. (2015b). Is science for us? Black students' and parents' views of science and science careers. Science Education, 99(2), 199-237. https://doi.org/10.1002/sce.21146.

Archer, L., Moote, J., Francis, B., DeWitt, J., \& Yeomans, L. (2017). The "exceptional" physics girl: a sociological analysis of multimethod data from young women aged 10-16 to explore gendered patterns of post-16 participation. American Educational Research Journal, 54(1), 88-126. https://doi.org/10.3102 /0002831216678379.

Aschbacher, P., Li, E., \& Roth, E. (2010). Is science me? High school students' identities, participation and aspirations in science, engineering, and medicine. Journal of Research in Science Teaching, 47(5), 564-582. https://doi.org/10.1002/tea.20353.

Ashby, J., \& Schoon, I. (2010). Career success: the role of teenage career aspirations, ambition value and gender in predicting adult social status and earnings. Journal of Vocational Behavior, 77(3), 350-360. https://doi. org/10.1016/j.jvb.2010.06.006.

Bandura, A. (1986). Social foundations of thought and action: a social cognitive theory. Englewood Cliffs: Prentice-Hall.

Bandura, A. (1989). Human agency in social cognitive theory. American Psychologist, 44(9), 1175-1184. https://doi.org/10.1037/0003-066X.44.9.1175.

Bandura, A. (1997). Self-efficacy: the exercise of control. New York: Freeman.

Bennett, J., \& Hogarth, S. (2009). Would you want to talk to a scientist at a party? High school students' attitudes to school science and to science. International Journal of Science Education, 31(14), 1975-1998. https:/doi. org/10.1080/09500690802425581.

Bøe, M. V., \& Henriksen, E. K. (2015). Expectancy-value perspectives on choice of science and technology education in late-modern societies. In E. K. Henriksen, J. Dillon, \& J. Ryder (Eds.), Understanding student participation and choice in science and technology education (pp. 17-29). Dordrecht: Springer. https://oi. org/10.1007/978-94-007-7793-4_2.

Bong, M., \& Skaalvik, E. (2003). Academic self-concept and self-efficacy: how different are they really? Educational Psychology Review, 15(1), 1-40. https://doi.org/10.1023/A:1021302408382.

Bosworth, D., Lyonette, C., Wilson, R., Bayliss, M., \& Fathers, S. (2013). The supply of and demand for highlevel STEM skills. London: UK Commission for Employment and Skills.

Bourdieu, P. (1984). Distinction: a social critique of the judgement of taste. (R. Nice, Trans.). Cambridge: Harvard University Press.

Bukodi, E., Goldthorpe, J., Waller, L., \& Kuha, J. (2015). The mobility problem in Britain: new findings from the analysis of birth cohort data. The British Journal of Sociology, 66(1), 93-117. https://doi.org/10.1111/14684446.12096 . 
Buschor, C. B., Berweger, S., Frei, A. K., \& Kappler, C. (2014). Majoring in STEM-what accounts for women's career decision making? A mixed methods study. The Journal of Educational Research, 107(3), 167-176. https://doi.org/10.1080/00220671.2013.788989.

Cannady, M., Greenwald, E., \& Harris, K. (2014). Problematizing the STEM pipeline metaphor: is the STEM pipeline metaphor serving our students and the STEM workforce? Science Education, 98(3), 443-460. https://doi.org/10.1002/sce.21108.

Claussen, S., \& Osborne, J. (2013). Bourdieu's notion of cultural capital and its implications for the science curriculum. Science Education, 97(1), 58-79. https://doi.org/10.1002/sce.21040.

Cohen, J. (1988). Statistical power analysis for the behavioral sciences (2nd ed.). Hillsdale: Lawrence Earlbaum Associates.

Crawford, C., Gregg, P., Macmillan, L., Vignoles, A., \& Wyness, G. (2016). Higher education, career opportunities, and intergenerational inequality. Oxford Review of Economic Policy, 32(4), 553-575. https://doi. org/10.1093/oxrep/grw030.

Department for Education. (2011). Maths and science education: the supply of high achievers at A level. Research report DFE-RR079. London: Department for Education.

DeWitt, J., \& Archer, L. (2015). Who aspires to a science career? A comparison of survey responses from primary and secondary school students. International Journal of Science Education, 37(13), 2170-2192. https://doi.org/10.1080/09500693.2015.1071899.

DeWitt, J., Archer, L., Osborne, J., Dillon, J., Willis, B., \& Wong, B. (2011). High aspirations but low progression: the science aspirations-careers paradox amongst minority ethnic students. International Journal of Science and Mathematics Education, 9(2), 243-271. https://doi.org/10.1007/s10763-010-9245-0.

DeWitt, J., Archer, L., \& Osborne, J. (2014). Science-related aspirations across the primary-secondary divide: evidence from two surveys in England. International Journal of Science Education, 36(10), 1609-1629. https://doi.org/10.1080/09500693.2013.871659.

DeWitt, J., Archer, L., \& Mau, A. (2016). Dimensions of science capital: exploring its potential for understanding students' science participation. International Journal of Science Education, 38, 2431-2449. https://oi. org/10.1080/09500693.2016.1248520.

DiPrete, T., \& Eirich, G. (2006). Cumulative advantage as a mechanism for inequality: a review of theoretical and empirical developments. Annual Review of Sociology, 32, 271-297. https://doi.org/10.1146/annurev. soc.32.061604.123127.

EACEA. (2011). Science education in Europe: national policies, practices and research. Brussels: European Commission. https://doi.org/10.2797/7170.

Eccles, J. (2009). Who am I and what am I going to do with my life? Personal and collective identities as motivators of action. Educational Psychologist, 44(2), 78-89. https://doi.org/10.1080/00461520902832368.

Eccles, J., \& Wang, M.-T. (2016). What motivates females and males to pursue careers in mathematics and science? International Journal of Behavioral Development, 40(2), 100-106. https://doi.org/10.1177 /0165025415616201.

Elias, P., Jones, P., \& McWhinnie, S. (2006). Representation of ethnic groups in chemistry and physics. London: The Royal Society of Chemistry and the Institute of Physics.

EngineeringUK. (2017). Engineering UK 2017: the state of engineering. London: EngineeringUK.

Fitzsimons, E., Agalioti-Sgompou, V., Calderwood, L., Gilbert, E., Haselden, L., Johnson, J., \& Smith, K. (2017). Millennium cohort study: sixth survey 2015-2016 user guide. London: UCL Institute of Education.

Gatsby. (2017). Key indicators in STEM education. London: The Gatsby Charitable Foundation.

Godec, S., King, H., \& Archer, L. (2017). The science capital teaching approach: engaging students with science, promoting social justice. London: University College London.

Homer, M., Ryder, J., \& Banner, I. (2014). Measuring determinants of post-compulsory participation in science: a comparative study using national data. British Educational Research Journal, 40(4), 610-636. https://doi. org/10.1002/berj.3106.

IBM. (2014). IBM SPSS missing values 22. IBM. Retrieved April 1, 2016, from ftp://public.dhe.ibm. com/software/analytics/spss/documentation/statistics/22.0/en/client/Manuals/IBM_SPSS_Missing_Values.pdf

Institute of Physics. (2012). The importance of physics to the UK economy. London: Institute of Physics.

Institute of Physics. (2013). Closing doors: exploring gender and subject choice in schools. London: Institute of Physics.

Institute of Physics. (2014). Raising aspirations in physics: a review of research into barriers to STEM participation for students from disadvantaged backgrounds. London: Institute of Physics.

Institute of Physics. (2015). Opening doors: a guide to good practice in countering gender stereotyping in schools. London: Institute of Physics.

Ipsos MORI. (2017). Millennium cohort study sixth sweep (MCS6): technical report. London: Ipsos MORI. 
Jenkins, E., \& Nelson, N. (2005). Important but not for me: students' attitudes towards secondary school science in England. Research in Science and Technological Education, 23(1), 41-57. https://doi.org/10.1080 $/ 02635140500068435$.

Jones, E., \& Ketende, S. (2010). User guide to analysing MCS data using SPSS. London: Institute of Education, University of London.

Macmillan, L., Tyler, C., \& Vignoles, A. (2015). Who gets the top jobs? The role of family background and networks in recent graduates' access to high-status professions. Journal of Social Policy, 44(3), 487-515. https://doi.org/10.1017/S0047279414000634.

Maltese, A., \& Tai, R. (2010). Eyeballs in the fridge: sources of early interest in science. International Journal of Science Education, 32(5), 669-685. https://doi.org/10.1080/09500690902792385.

Maltese, A., Melki, C., \& Wiebke, H. (2014). The nature of experiences responsible for the generation and maintenance of interest in STEM. Science Education, 98(6), 937-962. https://doi.org/10.1002/sce.21132.

Morgan, S., Gelbgiser, D., \& Weeden, K. (2013). Feeding the pipeline: gender, occupational plans, and college major selection. Social Science Research, 42(4), 989-1005. https://doi.org/10.1016/j. ssresearch.2013.03.008.

Moulton, V., Flouri, E., Joshi, H., \& Sullivan, A. (2018). Individual-level predictors of young children's aspirations. Research Papers in Education, 33(1), 24 41. https://doi.org/10.1080/02671522.2016.1225797.

Mujtaba, T., \& Reiss, M. J. (2014). A survey of psychological, motivational, family and perceptions of physics education factors that explain 15-year-old students' aspirations to study physics in post-compulsory English schools. International Journal of Science and Mathematics Education, 12(2), 371-393. https://doi. org/10.1007/s10763-013-9404-1.

OECD. (2015). The ABC of gender equality in education: aptitude, behaviour, confidence. Paris: OECD Publishing. https://doi.org/10.1787/9789264229945-en.

OECD. (2016). PISA 2015 results (volume I): excellence and equity in education. Paris: OECD Publishing. https://doi.org/10.1787/9789264266490-en.

Office for National Statistics. (2010a). Standard occupational classification 2010. Volume 1: structure and descriptions of unit groups. Basingstoke: Palgrave.

Office for National Statistics. (2010b). Standard occupational classification 2010. Volume 3: the National Statistics Socio-economic Classification: (rebased on the SOC2010) user manual. Basingstoke: Palgrave Macmillan.

Osborne, J., \& Dillon, J. (2008). Science education in Europe: critical reflections. London: The Nuffield Foundation.

Peugh, J., \& Enders, C. (2004). Missing data in educational research: a review of reporting practices and suggestions for improvement. Review of Educational Research, 74(4), 525-556. https://doi.org/10.3102 /00346543074004525.

Potvin, P., \& Hasni, A. (2014). Analysis of the decline in interest towards school science and technology from grades 5 through 11. Journal of Science Education and Technology, 23(6), 784-802. https://doi.org/10.1007 /s10956-014-9512-x.

Regan, E., \& DeWitt, J. (2015). Attitudes, interest and factors influencing STEM enrolment behaviour: an overview of relevant literature. In E. K. Henriksen, J. Dillon, \& J. Ryder (Eds.), Understanding student participation and choice in science and technology education (pp. 63-88). Dordrecht: Springer. https://oi. org/10.1007/978-94-007-7793-4 5.

Rose, D., \& O'Reilly, K. (1998). The ESRC review of government social classifications. London: Office for National Statistics.

Rose, D., Pevalin, D., \& O'Reilly, K. (2005). The National Statistics Socio-economic Classification: origins, development and use. Houndmills: Palgrave Macmillan.

Rosenberg, M. (1965). Society and adolescent self-image. Princeton: Princeton University.

Royal Society. (2006). A degree of concern? UK first degrees in science, technology and mathematics. London: The Royal Society.

Royal Society. (2008a). A higher degree of concern. London: The Royal Society.

Royal Society. (2008b). Science and mathematics education, 14-19: a 'state of the nation' report on the participation and attainment of 14-19 year olds in science and mathematics in the UK, 1996-2007. London: The Royal Society.

Royal Society. (2014). Vision for science and mathematics education. London: The Royal Society.

Schoon, I. (2001). Teenage job aspirations and career attainment in adulthood: a 17-year follow-up study of teenagers who aspired to become scientists, health professionals, or engineers. International Journal of Behavioral Development, 25(2), 124-132. https://doi.org/10.1080/01650250042000186.

Shaw, B., Menzies, L., Bernardes, E., Baars, S., Nye, P., \& Allen, R. (2016). Ethnicity, gender and social mobility. London: Social Mobility Commission. 
Sheldrake, R., Mujtaba, T., \& Reiss, M. J. (2017). Students' changing attitudes and aspirations towards physics during secondary school. Research in Science Education, 1-26. https://doi.org/10.1007/s11165-017-9676-5.

Sjaastad, J. (2012). Sources of inspiration: the role of significant persons in young people's choice of science in higher education. International Journal of Science Education, 34(10), 1615-1636. https://doi.org/10.1080 /09500693.2011.590543.

Social Mobility Commission. (2016). State of the nation 2016: social mobility in Great Britain. London: Her Majesty's Stationery Office.

Tai, R., Qi Liu, C., Maltese, A., \& Fan, X. (2006). Planning early for careers in science. Science, 312(5777), 1143-1145. https://doi.org/10.1126/science.1128690.

Tripney, J., Newman, M., Bangpan, M., Niza, C., MacKintosh, M., \& Sinclair, J. (2010). Factors influencing young people (aged 14-19) in education about STEM subject choices: a systematic review of the UK literature. London: Wellcome Trust.

Venville, G., Rennie, L., Hanbury, C., \& Longnecker, N. (2013). Scientists reflect on why they chose to study science. Research in Science Education, 43(6), 2207-2233. https://doi.org/10.1007/s11165-013-9352-3.

Vidal Rodeiro, C. (2007). A level subject choice in England: patterns of uptake and factors affecting subject preferences. Cambridge: Cambridge Assessment.

Wang, M.-T., Eccles, J., \& Kenny, S. (2013). Not lack of ability but more choice: individual and gender differences in choice of careers in science, technology, engineering, and mathematics. Psychological Science, 24(5), 770-775. https://doi.org/10.1177/0956797612458937.

Wigfield, A., \& Eccles, J. (2000). Expectancy-value theory of achievement motivation. Contemporary Educational Psychology, 25(1), 68-81. https://doi.org/10.1006/ceps.1999.1015.

WISE. (2014). "Not for people like me?" Under-represented groups in science, technology and engineering. Bradford: WISE.

Wong, B. (2015). Careers "from" but not "in" science: why are aspirations to be a scientist challenging for minority ethnic students? Journal of Research in Science Teaching, 52(7), 979-1002. https://doi.org/10.1002 /tea.21231.

Wong, B. (2016). Minority Ethnic Students and Science Participation: a Qualitative Mapping of Achievement, Aspiration, Interest and Capital. Research in Science Education, 46(1), 113-127. https://doi.org/10.1007 /s11165-015-9466-x. 